
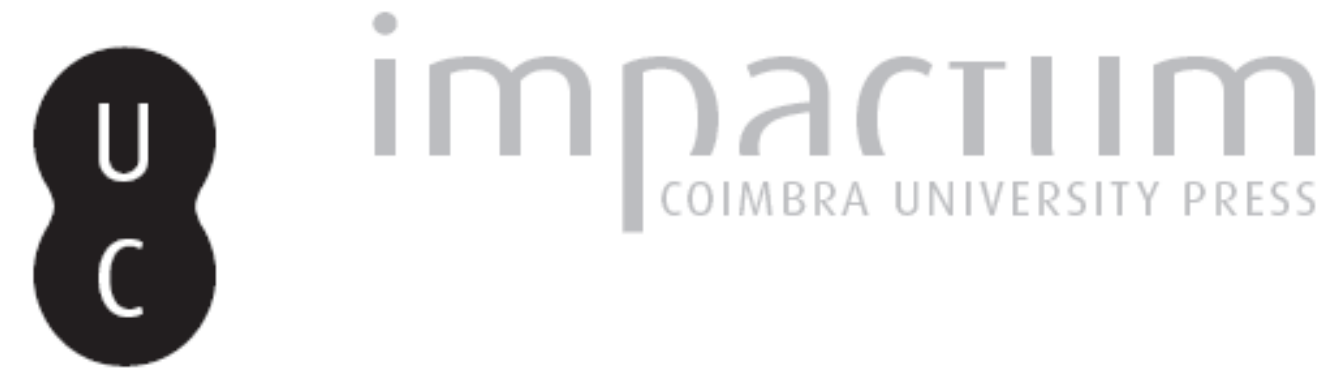

\title{
A electio verborum de Frederico II em De Arte Venandi cum Avibus
}

Autor(es): $\quad$ Silva, Manuel Augusto Naia da

Publicado por: $\begin{aligned} & \text { Associação Portuguesa de Estudos Clássicos; Instituto de Estudos } \\ & \text { Clássicos }\end{aligned}$

URL persistente:

URI:http://hdl.handle.net/10316.2/30311

DOI:

DOl:http://dx.doi.org/10.14195/0872-2110_57_5

Accessed : $\quad$ 26-Apr-2023 03:31:07

A navegação consulta e descarregamento dos títulos inseridos nas Bibliotecas Digitais UC Digitalis, UC Pombalina e UC Impactum, pressupõem a aceitação plena e sem reservas dos Termos e Condições de Uso destas Bibliotecas Digitais, disponíveis em https://digitalis.uc.pt/pt-pt/termos.

Conforme exposto nos referidos Termos e Condições de Uso, o descarregamento de títulos de acesso restrito requer uma licença válida de autorização devendo o utilizador aceder ao(s) documento(s) a partir de um endereço de IP da instituição detentora da supramencionada licença.

Ao utilizador é apenas permitido o descarregamento para uso pessoal, pelo que o emprego do(s) título(s) descarregado(s) para outro fim, designadamente comercial, carece de autorização do respetivo autor ou editor da obra.

Na medida em que todas as obras da UC Digitalis se encontram protegidas pelo Código do Direito de Autor e Direitos Conexos e demais legislação aplicável, toda a cópia, parcial ou total, deste documento, nos casos em que é legalmente admitida, deverá conter ou fazer-se acompanhar por este aviso.

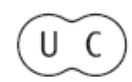




\section{Boletim de Estudos Clássicos}

Associação Portuguesa de Estudos Clássicos Instituto de Estudos Clássicos

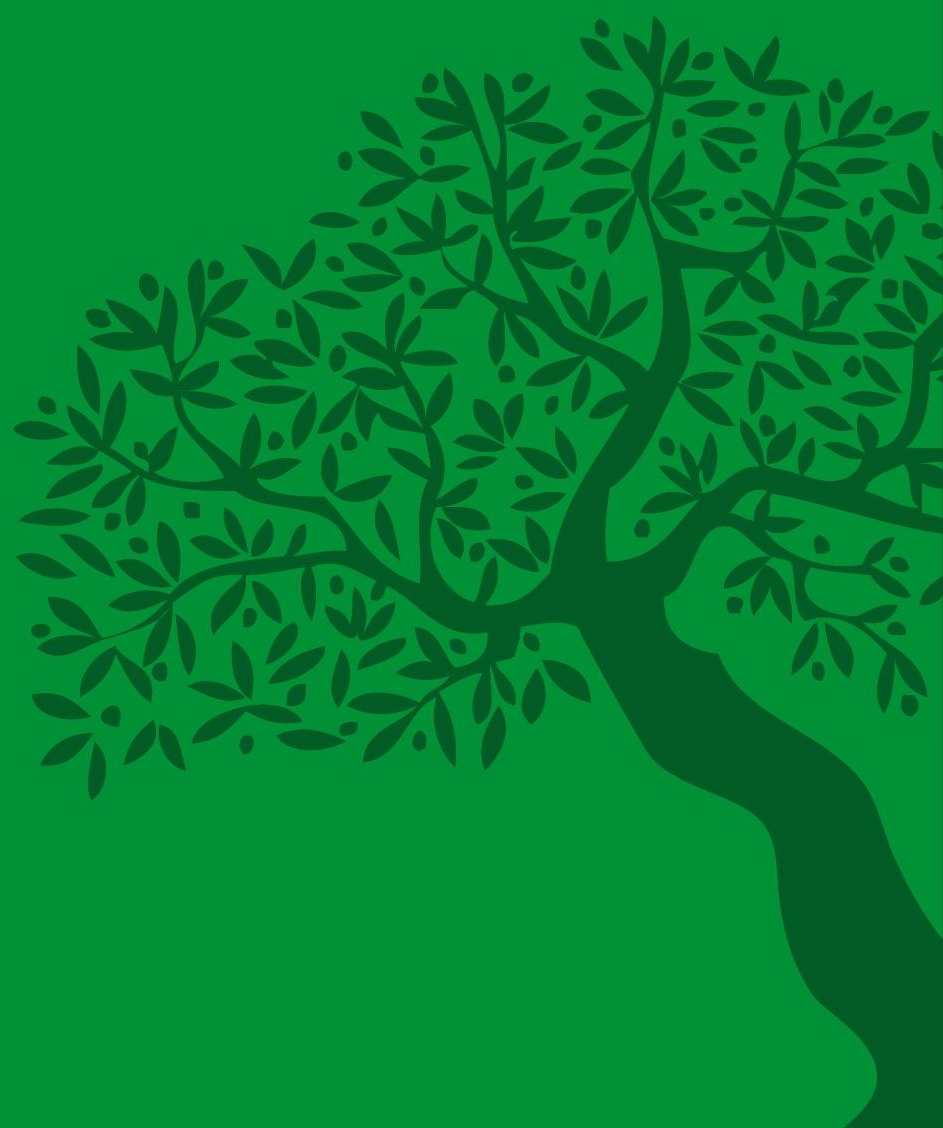

Coimbra

Junho de 2012 


\section{A ELECTIO VERBORUM DE FREDERICO II EM DE ARTE VENANDI CUM AVIBUS}

O mais antigo documento escrito em língua latina sobre a criação, o adestramento e, sobretudo, a veterinária aplicada a aves de presa intitula-se "Anónimo de Vercelli", que remonta ao séc. IX-X, retido na biblioteca capitular do mosteiro cujo nome lhe confere a designação. Trata-se de uma lista de remédios para debelar enfermidades próprias das aves. No século seguinte, surge o Liber accipitrum, da autoria de um tal mestre Grimaldo. Ao longo do séc. XII, o género literário cinegético afirma-se definitivamente. Por isso, outros escritos surgem nesta época ainda exarados em latim medieval, dispersos por diversas regiões: Dancus rex, Guillelmus falconarius, ambos da Sicília, Gerardus falconarius, da França meridional; De avibus tractatus, de Adelardo de Bath, autor inglês. Outros textos, sem localização geográfica identificada - Grisofus medicus, Alexander medicus, Epistola Aquila [...] ad Ptolomeum - emergiram na Península Ibérica em traduções mais ou menos conseguidas, com lacunas e lugares criativos.

$\mathrm{E}$ foi em meados do séc. XIII que surgiu o último escrito em língua latina - De Arte Venandi cum Avibus - cujo original, datado de 1240, se perdeu com o cerco de Parma em 1248. Esta obra da autoria de Frederico II de Hohenstaufen é dedicada a seu filho Manfredo, embora registe, de início, Miguel Escoto, astrólogo da corte, como interlocutor. Por isso, a marca do herdeiro imperial é verificável, por exemplo, quando o texto é introduzido pelo vocábulo "Rex" ou pela expressão "addidit rex". Uma mancha de sangue assente num dos fólios de um manuscrito é atribuída a este filho de Frederico II, eventualmente impregnada num dos períodos intercalares de alguma batalha. Frederico e seu filho Manfredo tiveram em vista um repositório deveras exaustivo ao longo de seis $\operatorname{livros}^{1}$, sendo o primeiro de carácter

1 Os dois primeiros livros são precedidos de um prólogo no sentido de enquadrar toda a obra. Quanto ao primeiro - "Incipit libri prologus de venatione avium rapacium" -, versa sobre o conteúdo, os fins e alguns aspectos de ordem formal. O segundo livro - "Incipit prologus libri secundi de venatione et de eius particulis" - inicia a série dos restantes livros sobre aspectos de ordem prática, desde 
genérico sobre ornitologia; o segundo sobre a criação e o adestramento das aves de presa e os restantes sobre os processos de caça ${ }^{2}$. Os aspectos farmocológicos e terapêuticos adequados, condição indispensável e quase única nos escritos anteriores redigidos em língua latina, desapareceram na letra, pois constavam somente no original perdido e não na versão de Manfredo que até nós chegou.

Não raro Frederico II se refere também às virtualidades desta arte no campo humanístico. Com efeito, a arte da falcoaria não se restringe meramente a uma técnica, mas pode redundar, até, em apelos a uma norma de vida que inclui a audácia, a memória, o engenho, o domínio dos próprios instintos pessoais. Dois outros registos parecem estar por detrás do escrito de Frederico: o Liber Animalium de Aristóteles, cuja versão em árabe foi traduzida por Miguel Escoto, astrólogo da corte, e a obra De Scientia Venandi per Aves, do árabe Moamyn, traduzida para latim por Teodoro de Antioquia da Síria. Até da língua persa Frederico II fez traduzir um documento intitulado Liber Ghatrif.

a caça $a o$ falcão até aos meios para caçar $o$ falcão. Segundo o índice geral, os livros são deste modo apresentados, seguidos dos diversos capítulos: 1. "Incipit liber primus de divisione generaliter avium in aquaticas, terrestres et medias, item in rapaces et non rapaces". 2. "Incipit liber secundus. De cognoscendis falconibus per formam membrorum et plumagium, comprehendens tantum formam et colorem pennarum, et de electione pulcriorum". 3. "Incipit liber tertius de instrumentis, per que redeant falcones ad homines". 4. "Incipit liber quartus de girofalco ad gruem, que et qualis fit venatio cum eo". 5. "Incipit liber quintus de falcone sacro ad airones". 6. "Incipit liber sextus de venatione fienda ad aves de rivera cum falcone peregrino".

2 Nas margens do texto, com a responsabilidade última de Manfredo, filho de Frederico II, regista-se uma quantidade considerável de imagens: 170 figuras humanas, mais de 900 espécies de aves, 12 cavalos, 36 raças diversas de animais, até aos instrumentos próprios da arte da falcoaria. O assédio de Parma fez desaparecer o original, assim como outros elementos do tesouro de Frederico. Depois da sua morte, em 1264, os seis volumes ficaram nas mãos do milanês Guilherme Botácio que os doou a Carlos de Anjou, perdendo-se, depois, o seu paradeiro. Uma cópia, em dois volumes, de Manfredo, filho de Frederico, que lhe acrescentou algo mais da sua autoria, encontra-se desprovida da parte última, que continha os aspectos farmocológicos do tratamento das aves. É a que se conserva na Biblioteca do Vaticano (Palatino Latino - 1071), tendo como suporte do texto um códice de pergaminho de 111 fólios a duas colunas. 
Poder-se-á admitir que os autores desta obra - Frederico e seu filho Manfredo - tenham recorrido a escritos precedentes como auctoritas ou base para a elaboração de um texto ilustrado, depois, com saberes provenientes da prática desta arte, desde a caça em geral até ao recurso específico a aves de presa como falcões, açores, gaviões. É perceptível o inacabamento deste surpreendente número de ilustrações que não colheram um término a preceito. Mas, por outro lado, tal indicia uma continuada investigação, como refere no prólogo do primeiro livro, em que o seu sentido crítico chega ao ponto de recusar informações de outros autores, como as de Aristóteles. A primeira tradução desta obra foi produzida para a língua francesa ao terminar o séc. XIII ou no início do séc. XIV. A primeira edição impressa foi levada a efeito em 1596 (Velser, Augsburgo) ${ }^{3}$.

O prólogo que antecede o primeiro livro desenvolve uma apresentação adequada a toda a obra: o título, o autor, o assunto, os fins, a disposição, a utilidade dos meios na matéria em questão, até aos instrumentos em uso na caça com aves de presa e à afirmação do apreço devido, a seu ver, à prática desta arte, em grande medida pelas suas virtualidades de carácter ecológico.

Mas é ainda antes das alíneas acima referidas, ao dirigir-se a Miguel Escoto, astrólogo da corte dos Hohenstaufen, que o autor contextualiza os seus propósitos: a débil fundamentação de escritos antes elaborados sobre a prática desta arte, inclusivamente da autoria de Aristóteles ${ }^{4}$, a espera de trinta anos, até ao momento presente, da decisão de passar a escrito tudo o que fora objecto de investigação, o recurso a técnicos requisitados de outras paragens a expensas suas. Por fim, aborda o problema da expressão em língua latina, em que vai desenvolver todo o manancial de conhecimentos comprovados pela sua prática:

3 Refiram-se as traduções modernas mais recentes: em língua inglesa, de Wood and Fyfe, 1943; em alemão, de C.A. Willemsen, 1964; em francês, de Baudouin van den Abeele et Anne Paulus, 2000; em italiano, de Trombetti-Budriesi, 2000; em castelhano, de Fradejas Rueda, 2004.

4 Ao dar início ao primeiro livro, o autor só aconselha, de Aristóteles, a leitura do que resta - reliqua vero omnia -, para além do que ele próprio passa a descrever sobre a prática - ubi, quando et quomodo - de caçar com aves de presa. É o que parece designar no prólogo do segundo livro como triplicem utilitatem ao tratar do finis sive causa finalis do seu escrito. 
«Rogamus autem unumquemque nobilem huic libro ex sua sola nobilitate intendere debentem, quod ab aliquo scientiarum perito ipsum legi faciat et exponi, minus bene dictis indulgens. Nam cum ars habeat sua vocabula propria quemadmodum et cetere artium et nos non inveniremus in gramatica Latinorum verba convenientia in omnibus, apposuimus illa, que magis videbantur esse propinqua, per que intelligi posset intentio nostra.» 5

Depois de apontar algumas circunstâncias que o moveram finalmente a passar a escrito todas as informações obtidas até ao momento, o autor reconhece dificuldades em cumprir os seus propósitos - «intentio nostra» para apresentar a ars de caçar com aves de presa, perante o leitor que pode aproveitar da leitura deste livro, isto é, o homem nobre movido exclusivamente pela sua condição social («ex sua sola nobilitate»). Teve sempre em mente o recurso a uma expressão adequada que não o afastasse dos termos «bene dictis». Terá esquadrinhado o que a língua latina lhe podia oferecer - «in gramática Latinorum» -, mas a conclusão redundará no reconhecimento da impossibilidade de alcançar os seus objectivos por impreparação própria ou, então, pela existência de lacunas no depósito vocabular disponível. Tratava-se, efectivamente, de recorrer a uma língua já por si só restringida a determinados círculos sociais ou em adiantada evolução que a desfigurava gradualmente, sobretudo a nível oral, e a requerer uma cuidada adaptação às novas condições de vida. Desta forma a copia verborum dos latinos já não resolvia o problema. A decorrente electio

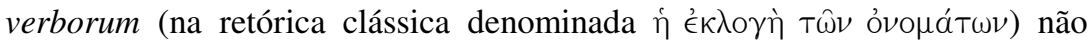
dispunha, assim, de uma base de sustentação e de escolha alargadas para veicular todo o arsenal de conhecimentos obtidos sobre a ornitologia em geral e sobre a criação, o adestramento, o tratamento de doenças e a arte de caçar com aves de presa.

Entre os vocabula ou verba distingue os propria, os convenientia e os propinqua. No primeiro caso - vocabula propria - refere-se ao campo semântico específico ao nível da arte em questão, onde é possível encontrar o termo adequado $(\pi \rho \in ́ \pi O \nu)$. Mas novas realidades, novos factos, novas circunstâncias advenientes dos resultados de ulteriores investigações

5 C. A. Willemsen, Frederici Romanorum Imperatoris Secundi De Arte Venandi cum Avibus, Lipsiae, in aedibus Insulae, MCMXLII, p. 2. 
implicavam necessariamente novas formas de expressão. E daí, a emergência de lacunas no vocabulário latino. Resultará, por isso, uma nova gama de empréstimos ou a formação de um quadro vocabular criativo. A verdade é que nem sempre é possível chegar à conformidade total por meio dos propria. Impunha-se, no entanto, encontrar registos coincidentes com os novos quadros civilizacionais e culturais, em que se desenvolvia também a arte venatória com aves de presa.

A conformidade ou impõe-se por si própria com vocábulos adequados então existentes no léxico latino - é o caso dos verba propria -, ou depende, em certa medida, de opções mais ou menos facultativas do autor ao formular a sua electio verborum. Neste segundo campo, situar-se-á certamente o uso dos verba propinqua, no contexto da procura dos convenientia. Por fim, há que referir o preenchimento das lacunas quando não conste qualquer vocábulo, nem sequer aproximado, a que se possa recorrer in gramatica Latinorum. É o que certamente se poderá comprovar ao longo de toda a obra.

Se tudo isto tem a ver com o início deste extenso documento sobre a caça del com aves de presa, já no prólogo que antecede o segundo livro verificamos, num capítulo à parte ("De Ordine"), uma evidente tomada de consciência das possibilidades de utilizar o material linguístico à disposição, depois do registo da «ordem» dos assuntos, assim como das operationes e dos instrumenta. A prova é que, para uso de certos vocábulos, houve de os citar expressamente sublinhando o seu valor semântico através do registo "id quod dicitur": malleolum, iacti, longa, sedilia, tiratorium, capellum, fileria, credentia, loyrum, trayna, ciroteca, muta...

Estes e outros vocábulos significativos na área dos instrumenta distribuem-se pelas diversas fases - operationes - do adestramento das aves de presa, como se refere nesse prólogo do segundo livro. Efectivamente o autor descreve um percurso desde in acquirendo (a caça ao falcão), passando por in detinendo/ mansuefaciendo/ instruendo/ docendo, até à caça com falcão, isto é, ad capiendum aves e ao seu bem-estar no que concerne à preservação da saúde: in conservando. Enfim - o que já ficara registado -, cumpria manter, como último objectivo, possuir e instruir as aves de presa: circa habendas et instruendas.

Para a caça - venatio - de/ com aves de presa reivindica-se a qualidade de uma ars, com características peculiares - quae ars. E superioriza-se nobilior est - a todas as outras formas de caçar, embora esta revele um certo grau de dificuldade - difficilior est -, pelo que exige conhecimentos teóricos confirmados por uma intensa prática. Estas propriedades são sublinhadas em 
ambos os prólogos. A parte teórica assenta em determinados princípios avalizados por uma teoria - per doctrinam/ principia -, com ensinamentos e regras - documenta et regulae -, de forma a evitar uma actividade meramente aleatória - casualiter.

Apesar da humilitas preventiva do autor em não poder veicular um léxico em língua latina plenamente adequado, a verdade é que registam-se pares de vocábulos de conteúdo aproximado como modus/ species, opus/ operatio, intentio/ propositum, com o primeiro a revelar um maior alargamento de sentido, em diversos contextos, permeando outros tantos campos semânticos. Ainda de realçar a repetição formal de um ou outro vocábulo quase sempre de nula relevância no discurso, reduzido à mera função fática da linguagem (v.g., hujusmodi, amplius).

Num relance por toda a obra, o vocabulário específico requerido passa por se revelar como que uma questão permanente. A título de exemplo, é de mencionar os vocábulos, por um lado, relativos à designação de determinadas espécies de aves como liverzinus, facha, coyardus, huanus, cofanus, e por outro, a enunciação de capítulos com o objectivo de explicitar certos meios próprios da arte, com epígrafes como «Quid est malleolum» ou «De forma capelli». Deste modo são recorrentes perífrases mais ou menos extensas sobre determinados vocábulos pelo menos em parte desconhecidos ou fora de uso.

As dificuldades de Frederico levam-no a distinguir formas semelhantes e a levantar suposições sobre a etimologia de certos vocábulos:

«Girofalco enim dicitur a iero, quod est sacer, inde gerofalco, id est sacer falco; vel a gyri, quod est dominus, inde girofalco, is est dominus falco secundum grecam linguam.» 6

O autor procura uma justificação recorrendo a étimos em língua grega: iefós (iero-) e kúplos (gyri-), com o sentido de sagrado e senhor, respectivamente. Sendo assim, faz-nos supor a sacralidade e o poder, num quadro social, por meio das denominações propostas de gerofalco e girofalco ${ }^{7}$.

${ }^{6}$ Cf. fol. 49v., in C. Willemsen, o.c., p. 22.

${ }^{7}$ Segundo a nota crítica de Laura Minervini (in Frederico II, De Arte Venandi cum Avibus, Lart de la chace des oisiaux, Facsimile ed edizione critica del manuscritto fr.12400 della Bibliothèque Nationale de France, Consorzio Editoriale Fridericiana, Electa Napoli, 1995, $1^{a}$ col. p. 592), tal distinção de carácter etimológico 
Por fim, é de assinalar a repartição dos assuntos inspirada em formulações peculiares da escolástica medieval dentro da minúcia em que normalmente tais processos se envolvem. Isso mesmo levou ao registo de títulos tais como de materia, de partibus materie, de modo agendi, de ordine, de fine sive de causa finali.

Cumpre ainda acentuar que os prólogos que iniciam cada um dos dois primeiros livros duma obra tão extensa e pretensamente exaustiva acabam por revelar também um mundo interior de quem o redige e, ainda, por realçar a procura tenaz de uma expressão linguística ao serviço de uma ars que, a juízo do autor, suscita um elevado grau de humanismo ${ }^{8}$.

\section{ACCIPITER STRIATUS}

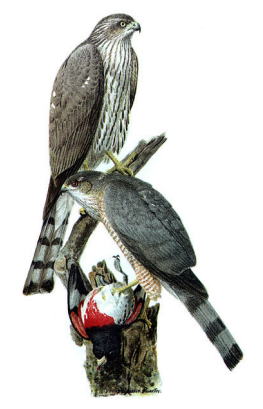

MANUEL AUGUSTO NAIA DA SILVA

não se revela com fundamento suficiente. Por sua vez, a denominação gerifalte, hoje usual, assume-se de proveniência anómala ou obscura ao terminar em -te (cf. in José Pedro Machado, Dicionário Etimológico da Língua Portuguesa, vol II, 2. a ed., Liv. Horizonte, 1967, s.u. "girafalte, girifalte").

8 Se quisermos encontrar referências mais remotas de carácter humanista,

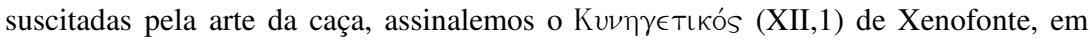
que se releva o amor pela pátria, a saúde física do indivíduo, o enobrecimento tanto do homem como da mulher. 